\title{
KÂULAK Y EL RETRATO FOTOGRÁFICO. VISUALIDAD Y REPENTISMO
}

\author{
JuAn Miguel SÁNChez VigiL ${ }^{1}$ \\ Universidad Complutense de Madrid
}

Toda fotografía es arte al ser susceptible de producir obras artísticas.

A. Cánovas. La Fotografía, julio de 1903

\begin{abstract}
El debate sobre la consideración artística de la fotografía fue una constante desde su presentación oficial en 1839. Uno de los principales autores en la historia de la fotografía española, Antonio Cánovas del Castillo Vallejo, Kâulak (1862-1933), reflexionó sobre el arte fotográfico y publicó sus conclusiones en las revistas del primer tercio del siglo XX, fundamentalmente en La Fotografía, creada por él en octubre de 1901. Cánovas abrió galería en 1904 y retrató a la sociedad madrileña hasta comienzos de los años treinta. Este artículo tiene por objeto presentar las reflexiones de Kâulak sobre el arte fotográfico y poner en valor su trabajo como retratista, destacando dos de las características que consideró fundamentales: la visualidad o fotogenia y el "repentismo" o capacidad de respuesta ante el comportamiento del modelo.
\end{abstract}

Palabras clave: Kâulak; retrato fotográfico; pictorialismo; fotogenia; "repentismo".

KÂULAK AND THE PHOTOGRAPHIC PORTRAIT. VISUALITY AND “REPENTISMO”

The debate over considering photography as an art has been constant since its official presentation in 1839. One of the leading authors in the history of Spanish photography, Antonio Cánovas del Castillo Vallejo, Kâulak (1862-1933), reflected on the art photography and published his conclusions in magazines of the first third of the $20^{\text {th }}$ century, principally in La Fotografia, which he founded in October of 1901. Cánovas opened his photographic studio in 1904 and made portraits of Madrid's society until the early 1930s. This article endeavors to present Kâulak's reflections on photographic art and highlight his portraits, focusing on two of their fundamental characteristics: their visuality or photogenic quality and their "repentismo" or capacity to improvise in response to the behavior of the model.

Key words: Kâulak; photographic portrait; pictorialism; photogenicity; "repentismo".

Cómo citar este artículo / Citation: Sánchez Vigil, Juan Miguel (2018): "Kâulak y el retrato fotográfico. Visualidad y repentismo". En: Archivo Español de Arte, vol. 91, núm. 363, Madrid, pp. 269-284. https://doi.org/10.3989/ aearte.2018.17.

1 jmsvigil@ucm.es / ORCID iD: http://orcid.org/0000-0002-1640-9295.

Copyright: (C) 2018 CSIC. Este es un artículo de acceso abierto distribuido bajo los términos de una licencia de uso y distribución Creative Commons Reconocimiento 4.0 Internacional (CC BY 4.0) 


\section{Introducción}

El valor artístico de la fotografía fue cuestionado en España hasta bien entrado el siglo XX, si bien los especialistas se posicionaron en pro del nuevo invento a través de la prensa y de los libros. Desde la invención de la fotografía, las galerías de retratistas proliferaron en toda Europa, especialmente en Francia e Inglaterra; en 1865 había en Londres más de doscientos estudios, la mayoría de ellos con medio centenar de empleados, lo que nos da idea del volumen de negocio ${ }^{2}$. Fueron por tanto, como afirma Sougez, "el gran motor de la divulgación de la fotografía"’. El género por excelencia fue el retrato, practicado por los amateurs y sobre todo por los profesionales, con una producción extraordinaria y de gran calidad. En el hecho de retratarse influyeron muchos aspectos, desde los estrictamente personales a la moda, y por supuesto a la posibilidad de perpetuar la existencia, como sugiere Ansón: "En el desdoblamiento de la imagen subyace el temor a la extinción, y fotografiarse es una forma de adelantar y ver nuestra ausencia desde los ojos del futuro"4.

En 1882 el polígrafo Felipe Picatoste planteó en su Manual de Fotografía la dualidad del fotógrafo como científico y artista: "No basta que sea un hombre de ciencia, sino que debe poseer además el sentimiento artístico, sin lo cual sus obras serán áridas reproducciones, sin belleza alguna" 5 . La última década del siglo XIX y los primeros años del XX fueron denominados por Alsina Munné "Época de la fotografía artística" nales se entregaron a la práctica y difusión a través de centros como el Camera Club de Viena fundado en 1887, el Photographic Salon de Londres creado en 1893, el Photo Club de París abierto un año más tarde en 1894, o el grupo Photo-Secession en Estados Unidos, que comenzó su actividad en 1902 bajo la dirección de Alfred Stieglitz?

En ese ambiente iniciaría su trabajo Antonio Cánovas del Castillo (Kâulak), uno de los autores españoles con mayor predicamento en lo que al retrato se refiere, y que lo practicó primero como amateur desde 1890 y después como profesional al frente del estudio que abrió en Madrid en 1904 en el número 4 de la calle Alcalá, junto a la Puerta del Sol. Entre los autores contemporáneos de Kâulak que teorizaron sobre la fotografía como arte se encuentra Antonio García Escobar, director de la revista Graphos Ilustrado, quien la describió como: "La reproducción de asuntos compuestos artísticamente, concebidos por la inspiración del fotógrafo, creados por él y obtenidos luego por placa sensible, tratada con la técnica necesaria a su mejor éxito"8. Este fue el planteamiento general de los profesionales en el primer tercio del siglo XX, período de actividad de Kâulak en el estudio, si bien hubo discrepancias como las del crítico y fotógrafo Luis Nueda, quien todavía en 1927 afirmaba que la fotografía carecía de inspiración y creación 9 .

Es objeto de este texto presentar las ideas de Kâulak sobre el arte fotográfico y poner en valor su aportación como retratista, destacando dos de las características que consideró fundamentales: la visualidad y el "repentismo". Como método, se ha contextualizado su aportación partiendo de la etapa pictorialista, se ha revisado la bibliografía sobre su vida y obra, y se han recuperado y analizado los artículos que sobre la materia publicó en la revista La Fotografía entre 1901 y 1913.

En cuanto al estado de la cuestión y las fuentes, indicaremos en primer lugar que sobre el pictoralismo se han consultado La fotografía pictorialista en España (Zelich, 1998) y "El impresionismo fotográfico en España" (King, 2000), y sobre el arte fotográfico "Arte y fotografía", en Historia General de la Fotografía (García Felguera, 2007) y Arte y fotografia (Scharft, 1994):

\footnotetext{
2 Scharf, 1994: 44.

3 Sougez, 1994: 245.

${ }^{4}$ Ansón, 2000:14.

5 Picatoste, 1882: 39.

${ }^{6}$ Alsina Munné, 1954: 73.

7 Scharf, 1994: 251.

${ }^{8}$ García Escobar, 1907: 156.

9 Nueda, 1927: 11.
} 
Sobre su vida y obra se han tomado como referentes el capítulo "De aficionado a profesional: el ejemplo de Kâulak" en Fotografía en España (1839-2015): Historia, tendencias, estéticas (Vega, 2017), Kâulak. Vida y obra del fotógrafo Antonio Cánovas del Castillo Vallejo (Sánchez Vigil, 2016), y el también capítulo "Los socios de la Real. Antonio Cánovas" en La forma fotográfica (Coloma, 1986). En lo que se refiere al retrato, además de los artículos publicados por el propio Cánovas en la revista La Fotografía y que se recogen en las referencias bibliográficas finales, es de especial interés el Tratado fotográfico sobre el retrato femenino. Antonio Cánovas "Kaulak" o el arte de la belleza (Carabias, 2002), en el que se estudia en profundidad la relación del fotógrafo con las mujeres y su materialización en las imágenes.

\section{Apunte biográfico de Kâulak}

Antonio Cánovas del Castillo Vallejo (Madrid, 1862-1933) fue sobrino del presidente del Gobierno Antonio Cánovas del Castillo, artífice de la Restauración borbónica en la persona de Alfonso XII, con una primera vocación política que abandonaría tras el asesinato de su tío en 1897. Desde 1884 fue funcionario del ministerio de Hacienda, representó a Cieza en las Cortes (1891-1895) y ejerció de gobernador civil en Málaga (1895-1897). Intelectual polifacético, desarrolló una intensa actividad fotográfica dividida en dos partes marcadas por la creación de la galería Kâulak: una amateur entre 1890 y 1904, y otra profesional desde éste año hasta su fallecimiento.

Estudió Derecho en la Universidad de Madrid y recibió clases de pintura del paisajista Carlos Haes. También tuvo formación musical, si bien no hay referencias al respecto. Fue crítico de arte, compositor, periodista y escritor. La crítica de arte en la prensa fue una de sus actividades más intensas entre 1892 y 1903, publicando cerca de un centenar de artículos en dos de los más prestigiosos diarios, La Época y La Correspondencia de España, en su mayoría relacionados con certámenes y exposiciones.

Firmó sus óleos y algunas de sus obras literarias con el seudónimo Vascano, formado con las tres sílabas de su apellido. En mayo de 1890 presentó un cuadro sobre la Iglesia de Valdemoro (Madrid) a la Exposición Nacional de Bellas Artes, comentado en La Ilustración Española y Americana ${ }^{10}$. Entre sus novelas, discretas según la prensa de la época, se encuentran Javier Malo (1884), El Mosén (1887) y Mocedades (1891) y la más tardía ;Pobres niños ricos! (1918). Publicó además el Ensayo biográfico del célebre navegante Juan de la Cosa (1892), el diccionario de inglés De Madrid a Londres (1899) y varias obras sobre arte, entre ellas El arte, el artista y la obra (1896), Apuntes para un Diccionario de pintores malagueños del siglo XIX (1908) y Rosales, biografía del pintor (1927). En lo que se refiere a la música, faceta menos conocida, fue autor de una decena de piezas (rigodones, valses, pasodobles, polcas, etc.), la mayoría fechadas a finales del siglo XIX, destacando por su relación con la fotografía Kâulak, vals brillante para bailar (1908), que compuso para obsequiar a los clientes que se retrataban en la galería.

$\mathrm{Su}$ actividad fotográfica amateur fue extraordinaria, dentro de la corriente pictorialista, participando en numerosos concursos y exposiciones nacionales e internacionales entre 1899 y 1904 , en los que obtuvo más de veinte galardones (París, Londres, Bruselas, Niza, San Petersburgo, Génova, Barcelona, Zaragoza y Madrid). Colaboró en la creación de la Sociedad Fotográfica de Madrid y fundó la revista La Fotografía en 1901, que dirigió hasta 1913 y en la que publicó más de trescientos artículos. Entre 1901 y 1905 editó cientos de tarjetas postales, algunas de cuyas series se comercializaron por millones, como ;Quien supiera escribir! basada en la dolora del mismo título de Ramón de Campoamor.

En el segundo período, acotado entre 1904 y 1933 como hemos indicado, puso en marcha el estudio Kâulak, uno de los más populares y prestigiosos de Madrid, en el que retrató a la familia real, la aristocracia y la burguesía. Participó en la Asamblea Nacional de 1905 y en la creación

10 Balart, 1890: 839. 
de la Sociedad General de Fotógrafos de España que surgió del evento, y en 1918 cofundó la sociedad nacional de empresarios Unión Fotográfica para la que dirigió la revista del mismo nombre. Escribió varios libros fruto de su experiencia, entre ellos La transformación de la fotografia (1906), La fotografía moderna (1912) y El retoque fotográfico (1921), organizó el archivo de su estudio con el fin de elaborar una iconografía, y publicó en las mejores revistas ilustradas: La Ilustración Española y Americana, Blanco y Negro, Mundo Gráfico, Nuevo Mundo, El Teatro o La Esfera.

\section{Kâulak pictorialista. La fotografía como arte}

El trabajo creativo de Kâulak se enmarca en la corriente pictorialista, surgida en Europa a finales del XIX y desarrollada entre 1880 y $1920^{11}$, y que en España continuaría hasta después de la Guerra Civil con una segunda generación de autores que se dieron a conocer a través de las revistas especializadas y las exposiciones internacionales. Su objeto fue la búsqueda de la belleza, en aproximación a la pintura, pero siempre reivindicando los valores de la fotografía. Roland Barthes lo definió como "Una exageración de lo que la foto piensa de sí misma"12, y Joan Fontcuberta explicó que este movimiento "Culminaba la tradición, especialmente esplendorosa en la Inglaterra victoriana, de la fotografía concebida como un esfuerzo de poetización de la realidad, en sintonía con las corrientes simbolistas y prerrafaelistas"13.

El referente teórico fue el libro Pictorial Effect in Photography ${ }^{14}$ del pintor y fotógrafo inglés Henry Peach Robinson, publicado en 1881. Carl S. King adjudica a George Davison y a su obra El campo de cebollas el comienzo de esta corriente o movimiento, así como a la conferencia Impressionism in Photography, que impartió en la Society of Arts de Londres el 19 de diciembre de $1890^{15}$. La temática de las obras fue diversa, desde el paisaje a las representaciones a través de la figura humana.

En España, como hemos comentado, hubo dos generaciones de pictorialistas con el año 1920 como línea divisoria, y Cánovas fue uno de los máximos representantes de la primera, como indica García Felguera: "En el área de influencia de Madrid la figura principal fue Kâulak"16. King compara su estilo con el del citado Robinson y el de los pictorialistas victorianos en cuanto a la narración de sus composiciones, con ejemplo en sus trabajos literarios de finales del siglo XIX y principios del XX que divulgó a través de las tarjetas postales ${ }^{17}$, y Vega pone en valor su "papel relevante en el desarrollo de las propuestas de la fotografía artística de principios de siglo" 18 .

Por otra parte, Kâulak contribuyó también a la difusión del pictorialismo en su función de editor, seleccionando textos de relevancia para la revista La Fotografía, entre ellos "La fotografía pictórica" de Constant Puyo, quien explicó el surgir del movimiento a finales del siglo XIX y lo vinculó al proceso técnico:

El problema consistía en modificar las distintas operaciones fotográficas, de manera tal que el artista pudiese, en el mayor grado posible, imprimir a la obra su personalidad. Para ello se imponía la sustitución de los procedimientos automáticos por otros en que la inteligencia y la sensibilidad propias del artista pudiesen intervenir en las mayores proporciones ${ }^{19}$.

\footnotetext{
11 García Felguera, 2007: 239.

12 Barthes, 1994: 71.

13 Fontcuberta, 2000: 78.

14 Robinson, Henry Peach (1881): Pictorial Effect in Photography. Filadelfia: Edgard L. Wilson.

15 King, 2000: 16.

16 García Felguera, 2007: 252.

17 King, 2000: 70.

18 Vega, 2017: 233

19 Puyo, 1912: 360.
} 
La obra pictorialista de Cánovas se caracteriza por la elección y preparación de espacios, la selección de modelos, la creación y diseño de decorados, y la composición, cuestiones que recoge Palenque y que considera un pilar fundamental en la reflexión acerca de las posibilidades y límites de la fotografía como arte ${ }^{20}$. Algunas de estas características en su etapa amateur fueron advertidas por sus contemporáneos, como la habilidad para colocar la figura en el paisaje, comparada con: "El papel en cierto modo análogo al que desempeña en los dramas líricos de Wagner la voz humana, no de elemento principal, sino de nota, aunque aislada, perfectamente harmónica, que sirve para dar valor, enlace y espíritu a todas las demás" ${ }^{21}$. En sus escritos se encuentran referencias que responden al interés por la reivindicación y difusión de la fotografía, así a propósito de la Exposición Nacional de Bellas Artes celebrada en Madrid en 1901 denuncia la falta de interés por la materia:

¿Por qué se habrá excluido de esta sección a la Fotografía?... Sin duda el autor del reglamento no la consideró tan decorativa como los azulejos de cartón piedra y los armarios de luna. Consolémonos los que tenemos afición a ese arte, infinitamente más arte y más decorativo que muchas de las cosas admitidas, con que nada menos que los expositores de la sección de Pintura han presentado (claro que no todos) hermosas fotografías iluminadas, instantáneas hábilmente obtenidas y otra porción de recursos que proporciona en abundancia el único arte excluido de la Exposición ${ }^{22}$.

Relacionó pintura y fotografía, situando a esta en un plano inferior, como arte menor o decorativa. Sobre ello publicó varios artículos sin cambiar de idea, tal vez por su vocación frustrada de pintor. Se confesó un apasionado de la foto como arte antes que como documento, por la característica de crear contenidos o asuntos que despertaran la sensibilidad: "Desde que contraje amistad con la Fotografía, vi que no tenía vocación sino para arrancarla su más sabroso fruto: el arte que puede producir"23. En 1903, en el artículo "La fotografía ¿puede o no puede ser arte?", manifestó que la clave se encontraba en el sentimiento y no en la herramienta, planteando que la valoración debía hacerse tras contemplar y analizar las obras de autores pictorialistas como Constant Puyo y Robert Demachy: "Toda fotografía es arte al ser susceptible de producir obras artísticas" 24 . Aun así no desdeñó su valor documental al captar la realidad antes de interpretarla: "La fotografía no es sino la estampación matemática del natural, un espejo que refleja el natural y lo hace perfectamente, con sus crudezas y aberraciones; pero que es, al fin y al cabo, el natural" 25 . También explicó su complementariedad al matizar que aunque algunos artistas vieron un enemigo en la cámara, otros la emplearon como instrumento de trabajo.

En la conferencia "La transformación de la fotografía" que pronunció en el Ateneo de Madrid en enero de 1906, y que había publicado en La Fotografía seis meses antes con el mismo título en cuatro entregas (mayo-agosto de 1905), expuso la evolución de la foto desde su invención en 1839 hasta finales del siglo XX, considerando que el cambio radical se produjo con el pictorialismo:

La fotografía ha vivido relegada al rango humilde de medio; el gusto, la imaginación y el arte la han convertido en fin. La última consideración de relevancia en cuanto al cambio se refiere al concepto, a la idea, antes incluso que a la expresión de la misma. Si en principio la fotografía fue experimental en el laboratorio, para pasar después a masificarse en las manos de los aficionados, fue precisamente un grupo de amateurs el que se apartó de la muchedumbre para elevar y dignificar la finalidad de sus trabajos con intención y aspectos artísticos ${ }^{26}$.

\footnotetext{
20 Palenque, 2013: 93.

21 “La fotografía artística”. En: Hojas Selectas, enero de 1906, pp. 444-448.

22 Cánovas, 1901: 4.

23 Cánovas, 1903: 101.

24 Cánovas, 1903b: 289.

25 Cánovas, 1903c: 53.

26 Cánovas, 1905: 323.
} 


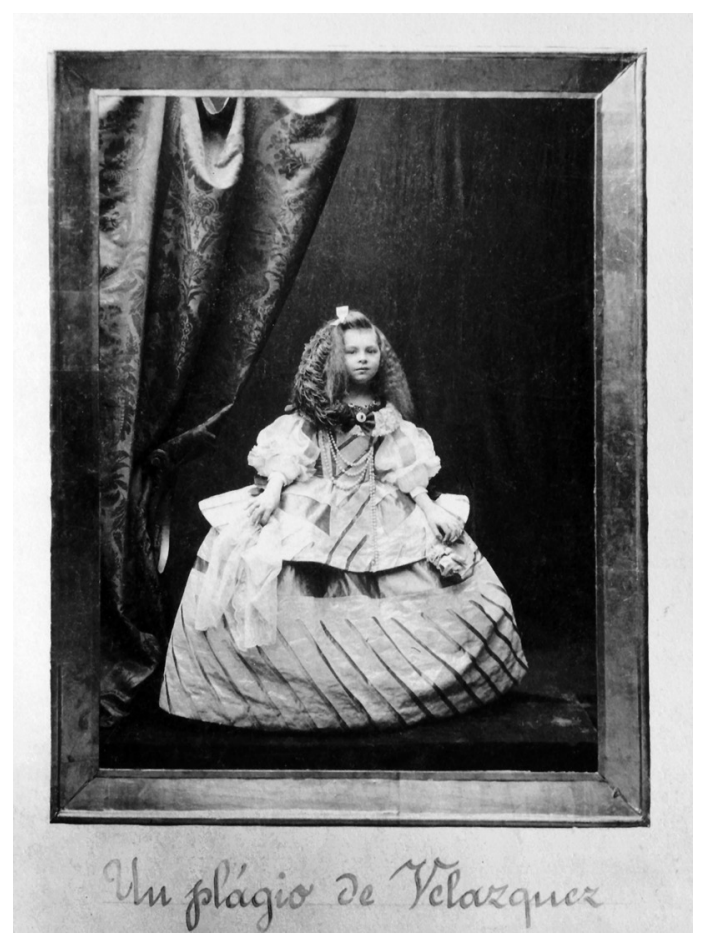

Fig. 1. Un plagio de Velázquez, 1900. Real Sociedad Fotográfica de Madrid.

En un artículo sin firma publicado en la revista Hojas Selectas en 1907 se reconoce a Kâulak como iniciador del movimiento artístico en España a propósito de una exposición de Pedro Casas Abarca: "Siguiendo el camino que, con lisonjeras esperanzas para el arte, inició Cánovas Vallejo, ha logrado Casas Abarca elevar la fotografía a gran altura como obra de arte" 27.

En "La fotografía artística", que se publicó también sin firma en Gran Vida en noviembre de 1908, se comenta la evolución desde las tomas relamidas de finales de siglo a la experimentación, eliminando los decorados recargados para buscar el arte en la naturalidad. Se indica que por encima de las reglas, como en el resto de las artes, está el sentimiento, y uno de los ejemplos vuelve a ser Cánovas: "Nosotros conocemos algunos señores que teóricamente nos han dejado asombrados, pero que en sus obras nunca han conseguido remedar la más mala de Kâulak cuando era aficionado".

En 1911, tras regresar de un viaje por Europa, manifestó su preferencia por las composiciones inglesas frente a las francesas: "En cuanto al arte fotográfico, es decir, a la delicadeza y belleza de las fotografías, es muy superior el de los ingleses que el de Francia, en la gran república la fotografía es más industria que arte, y en Inglaterra ocurre todo lo contrario"28. Estas reflexiones las resumiría después en el libro La fotografía moderna (1912), en el que indicó que los fotógrafos debían beber en las fuentes del dibujo o la pintura, o al menos conocer sus reglas para entender lo que estaban haciendo $^{29}$.

Estableció una línea divisoria entre las bellas artes y las artes plásticas, encuadrando en éstas últimas a la fotografía, calificándola como "estimable, de aprecio, pero nunca un arte suprema y pura", lo que no significaba que no pudiera ser artística y considerar artista a su autor. En 1912 rebatió las tesis del crítico de arte Dionisio Pérez, quien había publicado en Mundo Gráfico un texto laudatorio sobre el fotoperiodista Campúa (José Demaría López), refiriéndose a su obra informativa como artística. Entonces afirmó que la fotografía jamás estaría a la altura de las cinco grandes artes: música, pintura, escultura, poesía y arquitectura ${ }^{30}$.

\section{Los retratos de Kâulak. Visualidad y repentismo}

El retrato fue el género por excelencia en la obra de Kâulak, y sobre ello se pronunció en numerosos textos, especialmente en los artículos de La Fotografía. Su experiencia comenzó en la etapa amateur, con imágenes que luego editaría en tarjetas postales entre 1901 y 1905, siempre

\footnotetext{
27 “La Fotografía artística”. En: Hojas Selectas, n. " 85, mayo de 1907, p. 4.

28 Cánovas, 1911: 5.

29 Cánovas, 1912: 234.

30 Cánovas, 1912: 257.
} 
bebiendo en las fuentes de la pintura como manifestó en 1923 a propósito de la celebración en Madrid del III Salón Internacional de Fotografía: "No sé si retrato bien o mal; pero de lo que estoy seguro es de que cuanto sé, todo se lo debo al estudio constante del Museo del Prado"31.

Isidoro Coloma se aproxima a la obra de Kâulak desde los retratos, comparándolos con los de los grandes fotógrafos europeos como Nadar, Carjat y Adam-Salomon: "Sienta las bases de un tipo de imagen que ya será permanente en los profesionales españoles". Para Coloma los personajes retra-

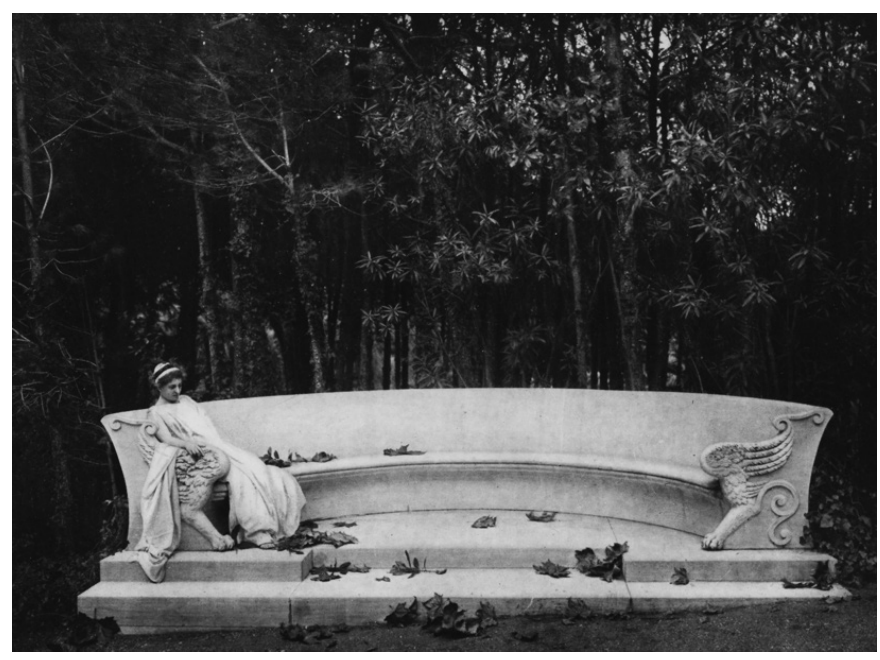

Fig. 2. Meditación, 1900. Archivo de $A B C$. tados llegan a "Trascender el aura de prestigio, dignidad, fama y popularidad que les rodea, para ofrecer una visión introspectiva y personal"32. Esta acertada visión podría aplicarse a cualquiera de los fotógrafos de estudio de la época en cuanto a la pretensión, pero no así en cuanto al resultado, como puede observarse en los retratos de Kâulak.

Dos de sus mejores obras en la etapa pictorialista, por originalidad, composición y fuerza expresiva, fueron Un plagio de Velázquez (fig. 1), que representa el retrato al óleo de la infanta Margarita de Austria pintado por Velázquez, con Piedad Iturbe como modelo, hija de la esposa del embajador de México Trinidad Iturbe, y Meditación (fig. 2), inspirada en un cuadro de Lawrence Alma Tadema, artista del que tomó como referencia muchos de los lienzos que reinterpretaban temas clásicos romanos y griegos ${ }^{33}$. Con estos trabajos Kâulak evidencia su "poetización de la realidad", y en esa imitación exagerada de la pintura muestra su afección al pictorialismo.

Otra de sus mayores aportaciones, donde se recreó con los retratos de los protagonistas, fue la mencionada serie ;Quién supiera escribir!, basada en la dolora de Campoamor y presentada al concurso fotográfico de la revista Blanco y Negro en 1900, en el que obtuvo los cinco premios convocados. Con estas imágenes realizaría dos series de tarjetas postales ${ }^{34}$ sobre las que Palenque ha escrito que la selección de versos impresos en cada una de ellas, considerada en su conjunto, conforma un nuevo poema ${ }^{35}$. Kâulak explicó las dificultades para realizar este tipo de trabajos en los que había que contar con escenarios y actores en el artículo "La ilustración de obras literarias por medio de la fotografía" 36 .

Del período pictorialista se conserva en la Biblioteca Nacional de España un conjunto de composiciones del natural (negativos en soporte vidrio) realizadas en Álora (Málaga), Beniaján (Murcia), Elche (Alicante) y Valdemoro (Madrid) entre otras localidades. En todas ellas incorpora tipos, solos o en grupo, imbricados perfectamente en el paisaje o escenario, conformando asuntos teatralizados que imitan a la pintura. Tomamos como ejemplo la fotografía titulada $L a$ lección, donde dirige a nueve personajes (ocho de ellos niños), que distribuye metódicamente de

\footnotetext{
31 Cánovas, 1923: 9.

32 Coloma, 1986: 155-157.

33 Alonso Laza, 2005: 203.

34 Sánchez Vigil; Olivera Zaldua, 2016: 67.

35 Palenque, 2013: 2.

36 Cánovas, 1908: 1-11.
} 


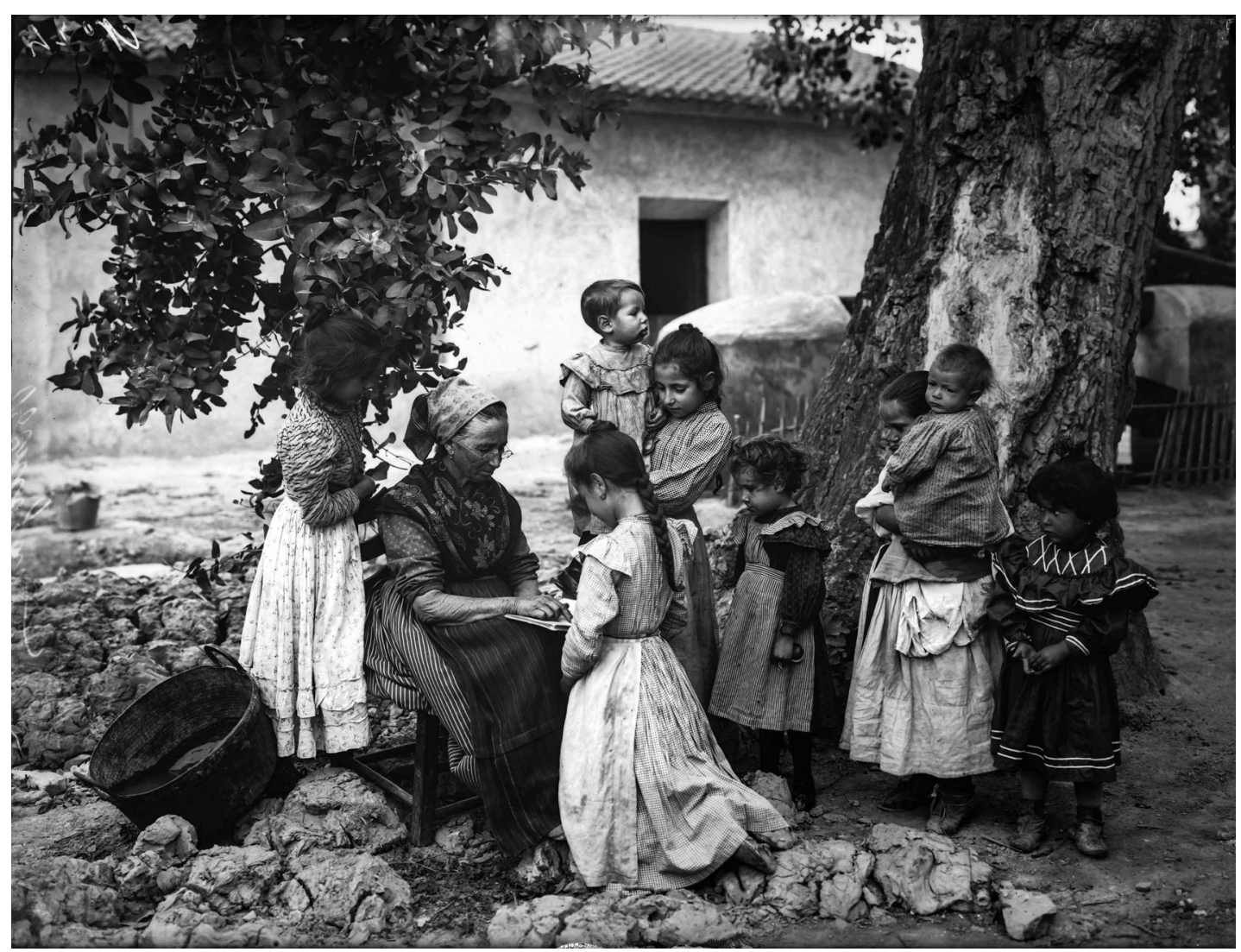

Fig. 3. Beniaján, Murcia. La lección. Biblioteca Nacional de España.

forma que el centro de la composición recae sobre la cabeza de una niña arrodillada. En otra fotografía, tomada en Valdemoro, se hacen insignificantes los personajes frente a la naturaleza, sin perder por ello protagonismo (figs. 3 y 4). Desde el punto de vista técnico la mayoría de las tomas son impecables tanto en el encuadre como en la iluminación.

En cuanto al retrato en el estudio, se vio claramente reflejada su experiencia como amateur, concibiendo las series como reportajes o conjuntos de composiciones en las que el fotógrafo es el director de la escena. El acto de retratarse en una galería fotográfica respondía o estaba vinculado generalmente a un momento trascendente de la vida, como la conmemoración de un hecho significativo, la pretensión de dejar constancia de la existencia o bien de construir la memoria. Para el autor, la dificultad consistía en captarlo o representarlo fielmente, en el sentido de obtener una imagen que fuera aceptada por el/la modelo, y que al mismo tiempo respondiera a su personalidad. En ese sentido Kâulak fue un psicólogo que analizó los comportamientos y la fisonomía del modelo con objeto de conseguir la mejor imagen, teniendo en cuenta los rasgos, gestos, poses, y otros detalles puntuales como el vestido o los accesorios elegidos como atrezo.

Para la realización del retrato estableció tres criterios generales: la colocación, la iluminación y la expresión, en un equilibrio con el mismo peso específico, es decir considerados a partes iguales, y ello partiendo de las herramientas y materiales adecuados: objetivo de calidad, placas bien sensibilizadas, tiempo de exposición correcto, y clichés suaves y transparentes. Utilizó la colocación como sinónimo de la composición, teniendo en cuenta la postura (frontal, de perfil, situación de la cabeza, manos y pies, según los planos), y la mirada (directa a cámara, indirecta, sesgada, etc.). El segundo criterio, la iluminación, tenía como función conseguir efectos mediante el manejo de la luz, natural o artificial, para con ello obtener relieves, profundidad, sombras, 
o cualquier otro resultado impactante. En cuanto a la expresión, al gesto, las reglas eran abiertas porque cada sujeto, cada tipo, cada fisonomía, requerían de un tratamiento diferente.

Además consideró otros dos aspectos de carácter técnico: la obtención del negativo y el positivado, es decir, la toma de la imagen y las operaciones de laboratorio para la consecución de las copias en papel, en las que valoró los procedimientos pigmentarios a la goma bicromatada, las tintas grasas o la colografía, empleada en la imprenta industrial ${ }^{37}$.

En 1912 presentó su idea del retrato en un capítulo específico del libro La fotografía moderna, considerándolo la más bella y artística de las aplicaciones, seguida del paisaje. Para explicar tal relación recurrió a la literatura, comparándolo con el soneto en la poesía: "Si el soneto es lo más supremo y arduo en la poesía, puede decirse que el soneto de la fotografía es el retrato" 38 .

Para Kâulak el modelo cobra todo el protagonismo, y en este sentido, sobre todo cuando se trata de artistas presentados en sus álbumes, los retratos constituyen el antecedente de los books o dossieres modernos, en muchos casos empleados como publicidad o carta de presen-

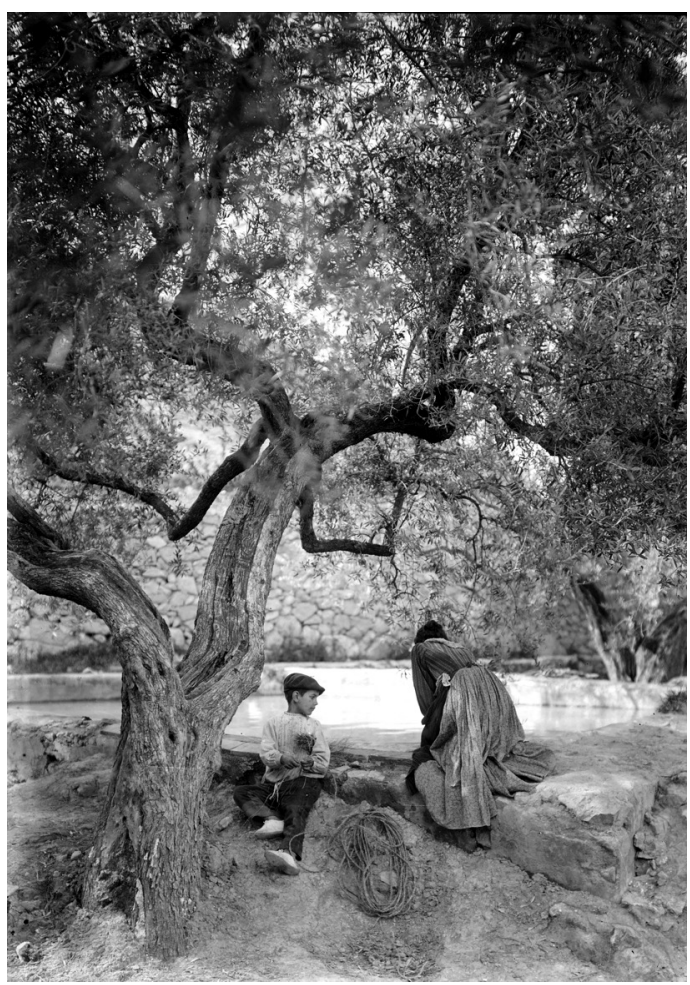

Fig. 4. Valdemoro. Composición pictorialista. Biblioteca Nacional de España. tación. El periodista Alfredo Escobar Ramírez, apodado Mascarilla, escribió sobre su metodología en 1913: "Prepara y compone a la manera de un Reynolds o un Gainsborough, quitando rigidez a las figuras, prestándolas vida" 39 .

En julio de 1915, con motivo de la celebración en Madrid de la Exposición Nacional de Fotografía Artística organizada por el Círculo de Bellas Artes, Ricardo Rivero Iglesias le destacó en Gran Vida por sus retratos, presentándole como el adalid del certamen. A esa muestra concurrieron numerosos autores, entre ellos el polifacético José Ortiz Echagüe y varios de los jóvenes que formarían parte de la segunda generación pictorialista: José Tinoco y Francisco Andrada (Madrid), José María Armengol (Barcelona), Vicente Martínez Sanz (Valencia), Enrique Guinea (Vitoria), Julio Peinado (Gijón) o Francisco Garay (Valladolid) ${ }^{40}$.

Es importante señalar que la clientela de su estudio fue mayoritariamente femenina, por lo que el retrato de mujeres fue su prototipo. Mónica Carabias en el excelente estudio sobre el retrato femenino de Kâulak indica que "sirvió en parte para reducir a las mujeres al más bello objeto a retratar" 41 . El mencionado Mascarilla le calificó como el "retratista de las bellas"42, sin embargo, la cantidad y calidad de estos retratos no desmerecieron a los masculinos como puede

${ }^{37}$ La colografía era una holografía sobre papel revestido de gelatina. Se practicó con papeles Double transfer fabricados para el carbón. El autor de este procedimiento fue el inglés Rawlius. Bajo esta forma se adoptó y perfeccionó en Francia por los miembros del Photo-Club de París. Reunía todas las cualidades que buscaban los fotógrafos pictóricos.

38 Cánovas, 1912: 163-168.

39 Mascarilla, 1913: 2.

40 Rivero Iglesias, 1915: 185-189; 207-210.

${ }^{41}$ Carabias, 2002: 12.

42 Mascarilla, 1913: 2. 


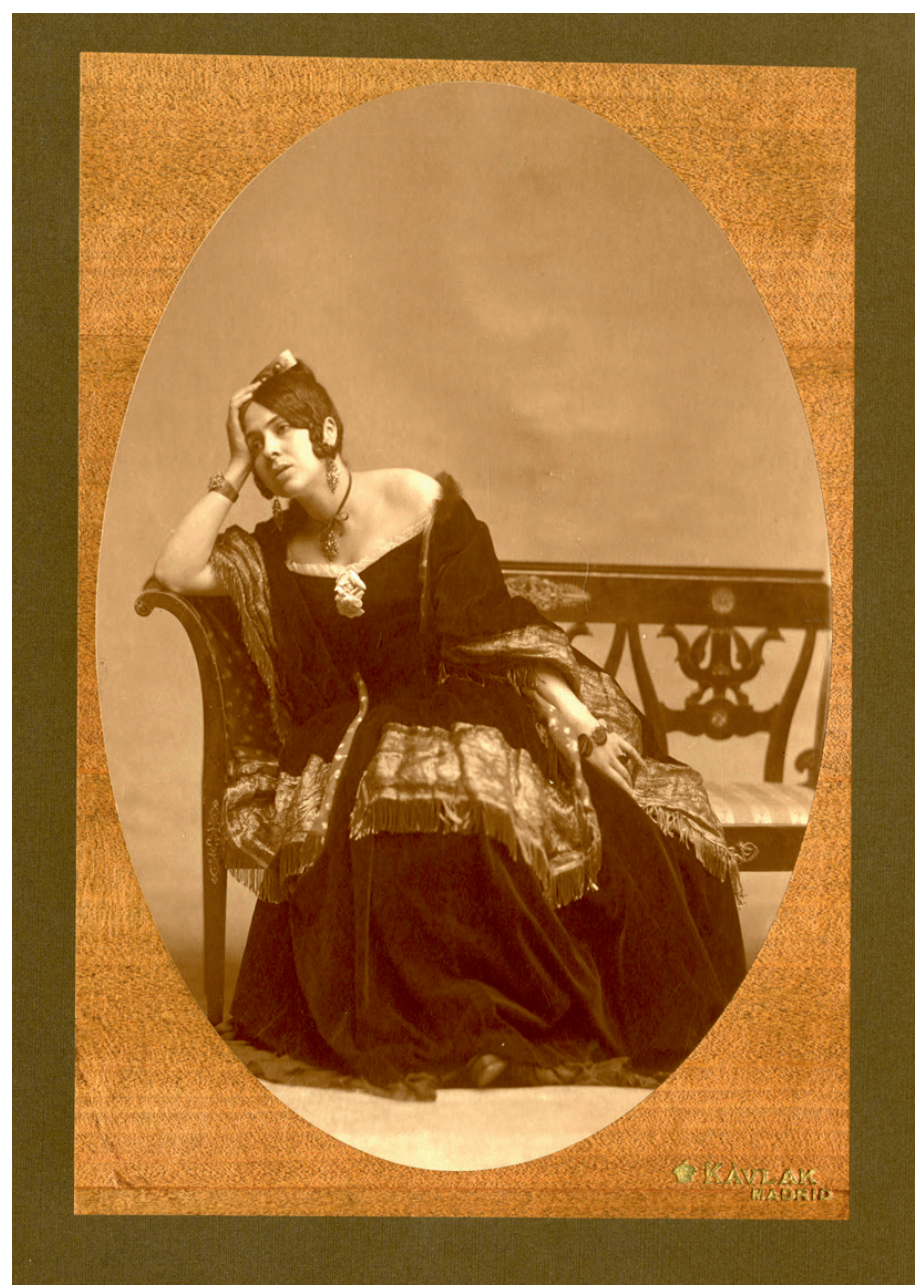

Fig. 5. Catalina Bárcena, 1919. Retrato dedicado a Joaquín Turina. Colección particular.

observarse en los numerosos originales conservados en la Biblioteca Nacional. El método para descubrir o aproximarse a la personalidad de la mujer lo explicó así: "La que aspire a retratarse bien debe entregarse incondicional y totalmente al fotógrafo, sin otras limitaciones que las que no son menester enumerar y que imponen el decoro y la buena educación"43.

Esta visión personal debe ser leída en el contexto social de comienzos del siglo XX, porque al contrario de lo que pueda entenderse se pronunció en favor de la igualdad de derechos, poniendo como ejemplo el estatus de las mujeres en Estados Unidos, Alemania o Inglaterra. El 15 de agosto de 1919 escribió en la revista Unión Fotográfica: "En Londres, en la casa de Miss Alice Hugues, la exquisita artista, no trabaja un solo hombre, y aquí, en Madrid, en plena Puerta del Sol, tenemos a la casa Kodak en la que, muchísimas muchachas, revelan, fijan, lavan, amplían, tiran y hacen cuanto hay que hacer en las fotografías".

El resultado de los retratos femeninos es sublime, como avalan las series de las actrices Carmen Viance, María Guerrero o Catalina Bárcena. También en el caso de los masculinos como el excelente de Benito Pérez Galdós (figs. 5 y 10). De Carmen Viance obtuvo más de doscientos, de los que 144 se encuentran en un precioso álbum con diversos formatos y presentaciones (óvalos, círculos y rectángulos), caracterizado por la diversidad de planos, algunos muy vanguardistas por su concepción y por los efectos de luz. El conjunto compone un excepcional catálogo donde se muestra su dominio de la luz y del encuadre, y su capacidad para captar los gestos ${ }^{44}$. De Catalina Bárcena se conservan los retratos reproducidos en 1925 en el libro Un Teatro de arte en España de Gregorio Martínez Sierra, galardonado con el Gran Premio de la Exposición Internacional de Artes Decorativas de París ese mismo año ${ }^{45}$.

43 Cánovas, 1905: 358.

44 Biblioteca Nacional, sig. Kâulak 7/45, 85 y 99; y LF/12

45 Un Teatro de arte en España fue el nombre de la empresa puesta en marcha por Martínez Sierra y su amante, la actriz Catalina Bárcena, en el teatro Eslava de Madrid entre 1916 y 1927. Su característica fue la puesta en valor de las artes plásticas, los decorados y el vestuario en las obras. 

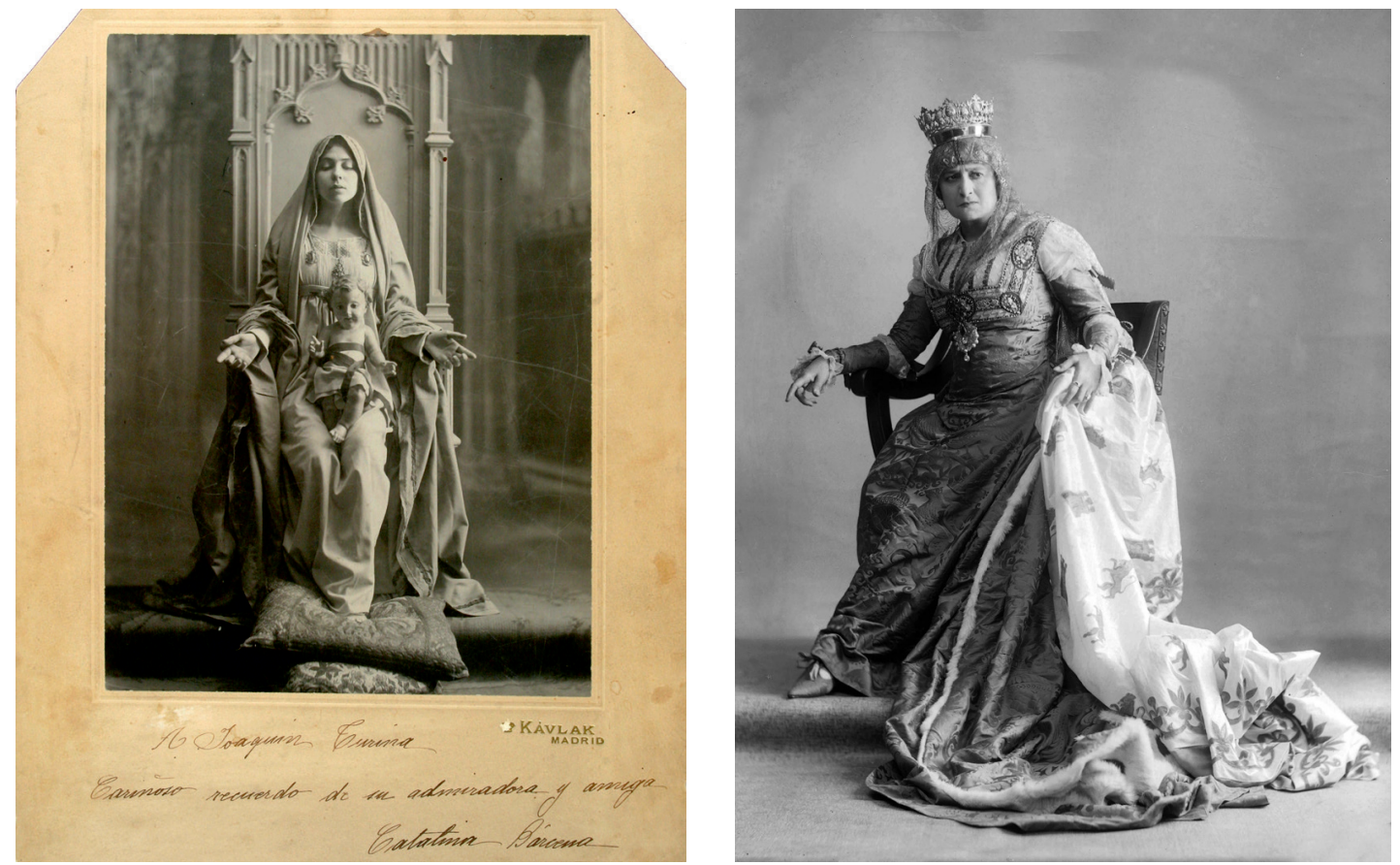

Figs. 6-7. Catalina Bárcena en La dama de las camelias. Traje de José Zamora. Publicada en Un Teatro de Arte en España de Gregorio Martínez Sierra, 1925 Colección particular. María Guerrero como Isabel de Castilla. Biblioteca Nacional de España.
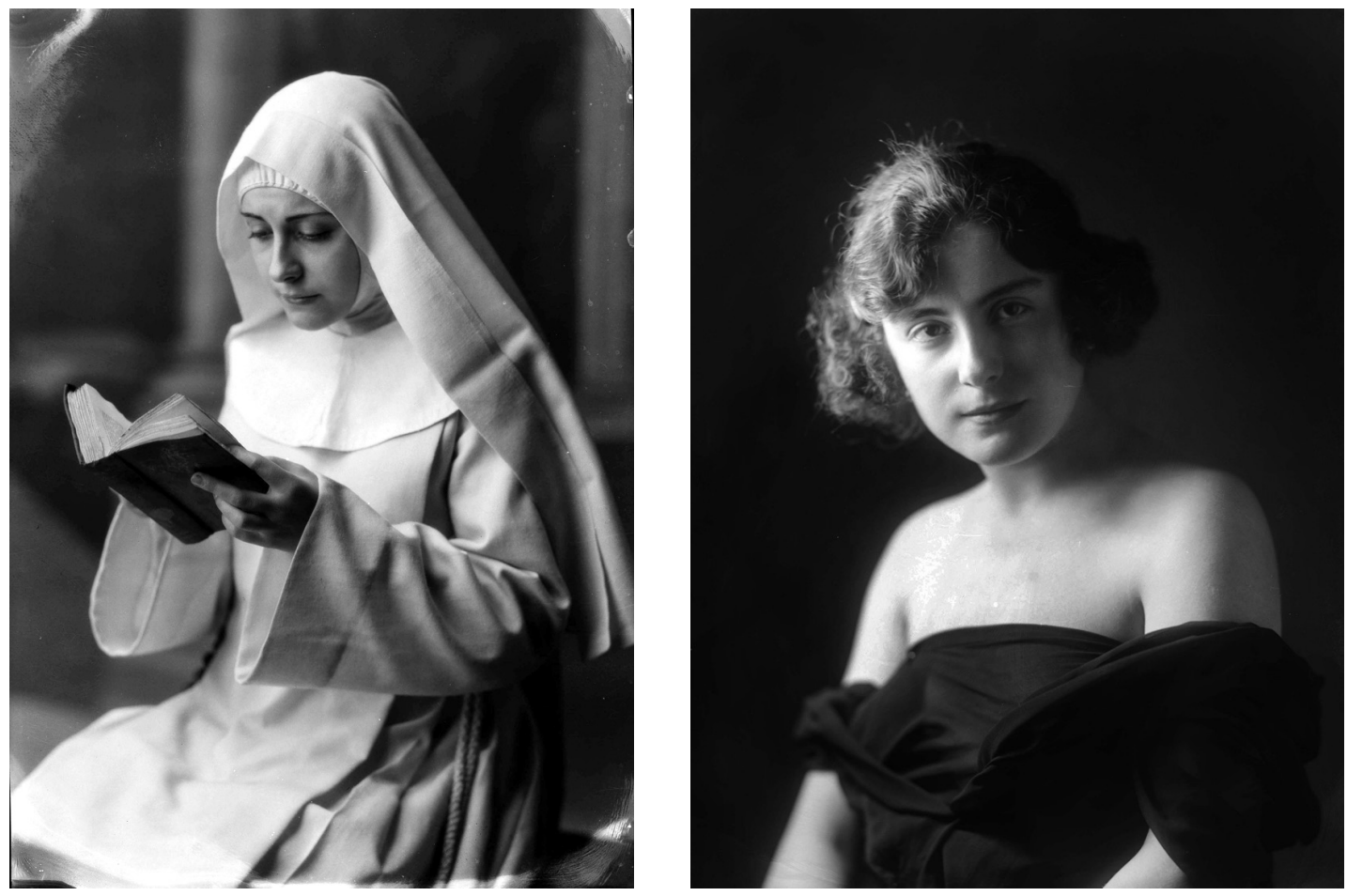

Figs. 8-9. Carmen Viance. Biblioteca Nacional de España.

Archivo Español de Arte, vol. XCI, n. ${ }^{\circ}$ 363, pp. 269-284, julio-septiembre 2018 ISSN: 0004-0428, eISSN: 1988-8511, https://doi.org/10.3989/aearte.2018.17 


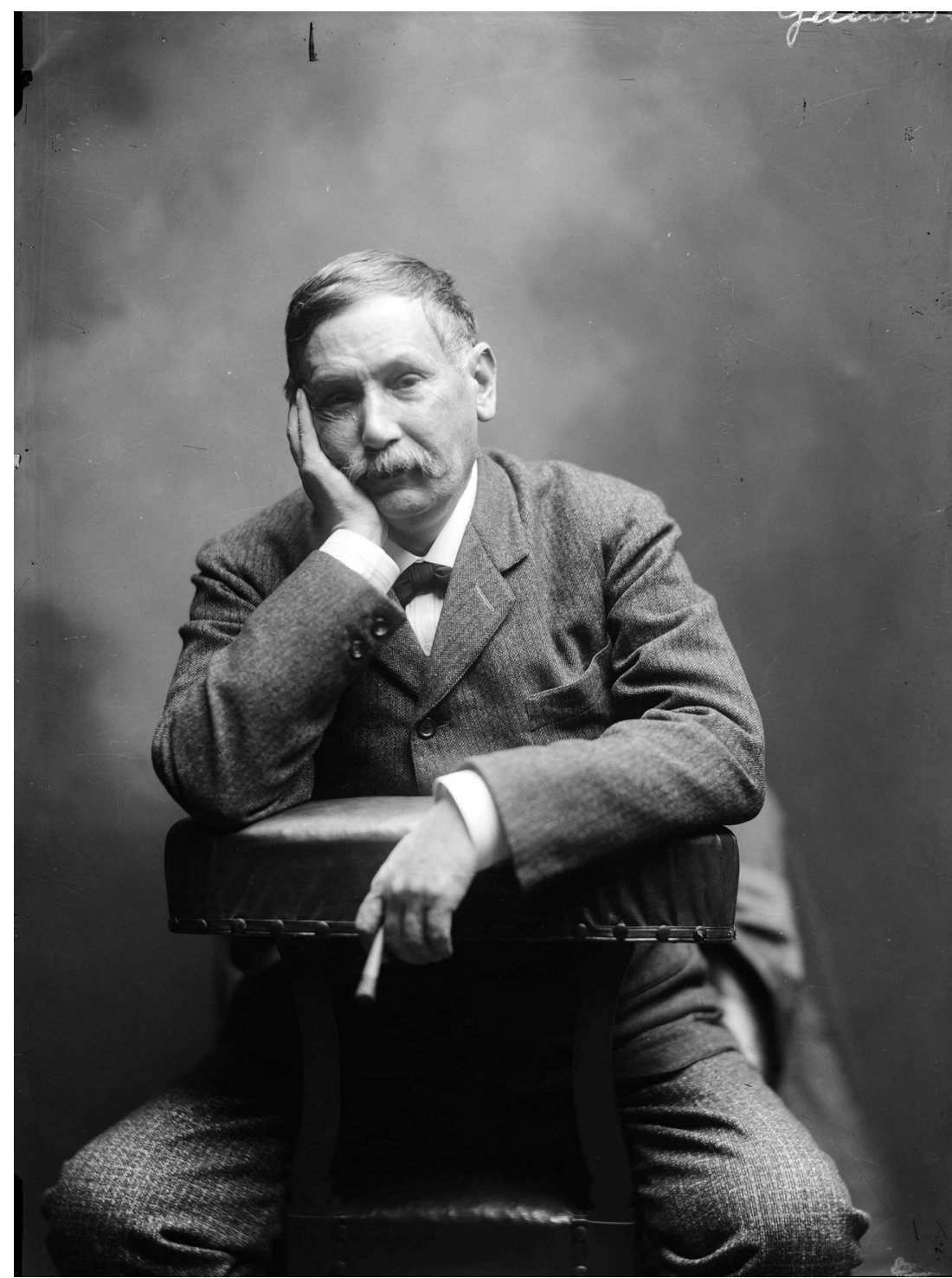

Fig. 10. Benito Pérez Galdós. Biblioteca Nacional de España.

Otro ejemplo lo encontramos en María Guerrero, de la que se conservan una treintena de retratos magistrales ${ }^{46}$ en los que presenta todo el repertorio de posibilidades técnicas y creativas: encuadres, foco e iluminación impecables; primeros planos, generales, americanos y medios; tomas frontales, perfiles, semiperfiles y de espaldas; picados y contrapicados, además de los recursos del gesto (miradas, rostro, torso, manos, etc.), y de los elementos complementarios (mobiliario, vestuario y fondos o forillos de la galería).

Kâulak acuñó dos términos sobre el retrato a finales de la primera década del siglo XX, cinco años después de abrir el estudio: visualidad y repentismo. En marzo de 1909 se refirió a la visualidad en el artículo "Retratos fotográficos" con el que inauguró la sección "La Fotografía" de El Heraldo de Madrid. La visualidad o visualitas es definida por la Real Academia como el "efecto agradable que produce el conjunto de objetos vistosos", por lo que aplicada al retrato

46 Biblioteca Nacional, sig. Kâulak 7/19 
sería el efecto agradable transmitido por la persona fotografiada. La hipótesis, confirmada en la práctica, era que el resultado de una buena imagen radicaba en la actitud del retratado antes que en el retratista: "Lo que se pone ante el objetivo, si es vistoso, agradable y pintoresco, saldrá amable y con visualidad; si es antipático y grosero, resultara desagradable" $"$.

En cuanto al repentismo, el término no lo recoge el Diccionario de la Real Academia, pero si repentizar y repente, definidos como "improvisar con rapidez" y "movimiento súbito o no previsto". Kâulak lo utilizó para definir la capacidad de respuesta ante el comportamiento del modelo, con el fin de obtener y/o captar la mejor imagen. Se refería al profesional capaz de improvisar en una situación específica, factor clave en el retrato. En el análisis de sus trabajos encontramos dos ejemplos que explican estas consideraciones: los reportajes de Mata Hari y los de Alfonso XIII y la reina Victoria Eugenia, realizados con dos años de diferencia en 1908 y 1910.

En marzo de 1908 la célebre artista

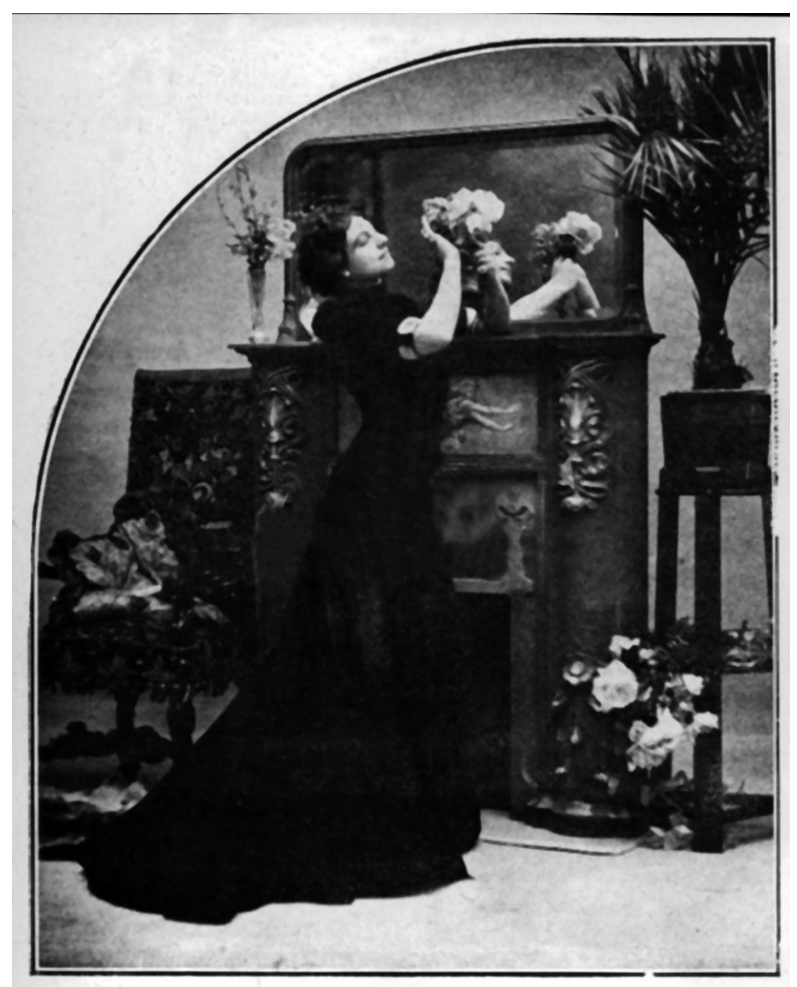

Fig, 11. Mata Hari, por Kâulak. La Fotografía, abril de 1908. Archivo de $A b c$. y bailarina Mata Hari visitó el estudio, probablemente invitada con la pretensión de retratarla y mostrar así las fotografías en el portal de la galería como atracción para la clientela (fig. 11). En el número de abril de La Fotografía se reprodujeron tres retratos vestida de negro y en distintas poses, de los que dos ilustran los artículos "En la galería Kâulak" y "El repentismo en la fotografía", dedicados como hemos señalado a la improvisación del fotógrafo, a su capacidad para interpretar la escena e inventar; es decir, de repentizar. Cánovas lo consideró condición esencial, intrínseca en la actividad del autor. La referencia a Mata Hari no es explícita sino indirecta y ciertamente misteriosa, y la realiza en el primer texto para indicar la importancia de las actitudes de las personas al retratarse y la ventaja de contar con modelos capaces de posar con la mínima intervención del autor.

En cuanto a los retratos de Alfonso XIII y Victoria Eugenia (fig. 12), son un claro ejemplo de la capacidad del fotógrafo para improvisar, puesto que los monarcas contaban con poco tiempo cada vez que visitaban el estudio, por lo que sus actitudes o gestos dependían de un instante, sin posibilidad de repetir las tomas en otras sesiones. Kâulak realizó la más completa colección de retratos de los reyes, captando siempre su personalidad. Durante la Navidad de 1909 y en los primeros días de enero de 1910 se expusieron en las vitrinas del portal de la galería 25 retratos, montados en un panel que constituyó un espectáculo en el centro de Madrid y que fue muy alabado por la prensa. El pintor Apeles Gómez puso en valor la muestra destacando la agilidad del fotógrafo para afrontar y responder al compromiso:

Esos veinticinco retratos conseguidos, representan un esfuerzo considerable realizado en brevísimo tiempo, significan un mérito, no digamos del fotógrafo, sino de la fotografía y de los que

47 Cánovas, 1909: 17. 


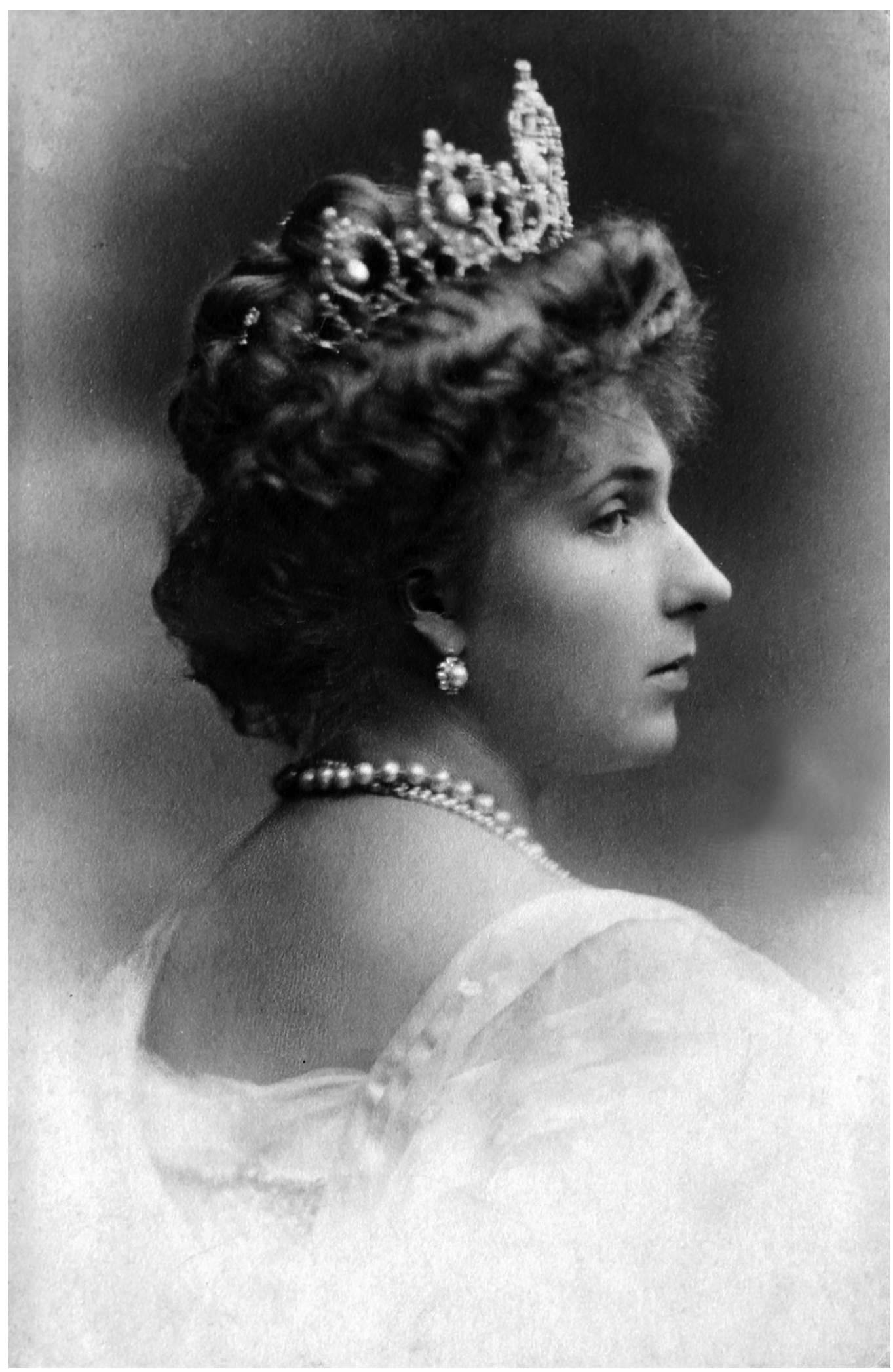

Fig. 12. La reina Victoria Eugenia de Battenberg. Colección particular.

Archivo Español de Arte, vol. XCI, n. ${ }^{\circ}$ 363, pp. 269-284, julio-septiembre 2018 ISSN: 0004-0428, eISSN: 1988-8511, https://doi.org/10.3989/aearte.2018.17 
la practican a diario. Cualquier pintor de los que alardean de fáciles e improvisadores, se vería y se desearía para poner en un día entero las 25 posiciones en que aparecen retratados... Claro está, que no todos son buenos (alguno hay que no me gusta nada), pero, en su mayoría, son verdaderos aciertos, y, según se dice, S. M. el Rey no estuvo en la galería de marras sino media hora. Pues bien, yo que soy pintor y que he tenido el honor de hacer un retrato de un miembro de la familia Real (alcanzando la fortuna de que viniese a mi estudio concediéndome cinco sesiones), debo declarar y declaro que, sólo en colocar a mi augusto modelo, invertí dos mañanas dudando y vacilando mucho antes de determinar la postura, el ademán, la iluminación, la colocación de manos y de $\operatorname{pies}^{48}$.

\section{Conclusiones}

Antonio Cánovas del Castillo Vallejo (Kâulak) fue considerado por sus contemporáneos, y posteriormente por los historiadores, estudiosos e investigadores, uno de los grandes autores españoles del primer tercio del siglo XX, y uno de los clásicos de la primera generación de pictorialistas. Llevó a cabo una extensa obra caracterizada por el retrato, tanto en su etapa amateur (1895-1904) como profesional en la galería (1905-1933):

Sus composiciones pictorialistas reflejan la corriente artística del momento, si bien fue con el retrato donde desarrolló en mayor medida su creatividad, especialidad que practicó habitualmente y que estudió con interés. Desde la revista La Fotografía, entre 1901 y 1913, dinamizó la cultura fotográfica, y para esa publicación escribió numerosos artículos sobre el arte fotográfico y específicamente sobre el retrato, explicando su valor frente al dibujo y la pintura, así como la importancia del mismo como género. Teorizó sobre la forma de realizar los retratos, estableciendo como criterios esenciales la composición, la iluminación y la expresión.

La visión de Kâulak sobre el arte fotográfico en general viene a aportar a la historia de la fotografía, y por extensión a la historia del arte, nuevos datos sobre la percepción de los propios autores, en ocasiones ambiguas o contradictorias. Dividió el arte en dos niveles, bellas artes y artes plásticas, situando a la fotografía en el segundo por considerarla inferior a la arquitectura, la pintura o la escultura, consideraciones que resultan ciertamente controvertidas, debido probablemente a su formación pictórica y en consecuencia a la influencia que tuvo la pintura en su obra.

En lo que se refiere al retrato, además de considerarlo el género por excelencia, acuñó dos términos originales: visualidad o fotogenia y repentismo o capacidad de respuesta del autor ante el comportamiento del o la modelo. Ambos términos nos permiten entender su metodología de trabajo y por extensión la de los retratistas del primer tercio del siglo XX, basada en la composición y en el gesto.

Por último, y como complemento a la aportación de Kâulak a la cultura de la imagen, hemos de indicar que durante su larga trayectoria como amateur y profesional conformó un extraordinario archivo de retratos, en gran parte conservados en la Biblioteca Nacional de España (negativos y positivos), que trascienden el tema que aquí se estudia y que permiten trabajar en nuevas vías de investigación relacionadas con la sociedad, la antropología, la moda o la psicología, entre otras materias.

\section{BIBLIOGRAFÍA}

Alonso Laza, Manuela (2005): La fotografia artística en la prensa ilustrada. (España 1886-1905): Madrid: Universidad Autónoma (Tesis Doctoral).

Alsina Munné, Hermenegildo (1954): Barcelona: Producciones Editoriales del Nordeste.

Ansón, Antonio (2000): Novelas como álbumes. Fotografía y literatura. Murcia: Mestizo.

48 Gómez, 1910: 126-127. 
Balart, Federico (1890): “La Exposición Nacional de Bellas Artes”. En: La Ilustración Española y Americana, 30 de mayo, pp. 839-840.

Barthes, Roland (1994): La cámara lúcida. Barcelona: Paidós.

Cánovas, Antonio (1901): "Exposición Nacional de Bellas Artes (XII): Arte decorativo”. En: La Época, 27 de mayo.

Cánovas, Antonio (1903): "El arte en fotografía". En: Hojas Selectas, enero, pp. 99-103.

Cánovas, Antonio (1903b): “La fotografía, ¿Puede o no puede ser arte?”. En: La fotografía, julio, pp. 289-296.

Cánovas, Antonio (1903c): "Utilidad de la fotografia para los artistas". En: La Fotografía, noviembre, pp. 52-54.

Cánovas, Antonio (1905): "La transformación de la fotografía”. En: La Fotografia, junio, p. 258, y agosto, p. 323.

Cánovas, Antonio (1908): "La ilustración de obras literarias por medio de la fotografía. Historia de unas tarjetas postales". En: La Fotografia, marzo, pp. 2-11.

Cánovas, Antonio (1909): "Retratos fotográficos”. En: El Heraldo de Madrid, p. 11.

Cánovas, Antonio (1910): “Retratos fotográficos”. En: La Fotografia, marzo, pp. 17-18.

Cánovas, Antonio (1911): “Impresiones de un viaje”. En: La Fotografia, octubre, p. 5.

Cánovas, Antonio (1912): “¿La fotografía es arte?”. En: La Fotografia, septiembre, pp. 257-264.

Cánovas, Antonio (1920): “La fotografía y la literatura”. En: Unión Fotográfica, enero, p. 11.

Cánovas, Antonio (1923): “El Retrato”. En: Unión Fotográfica, primer trimestre, p. 9.

Cánovas del Castillo Vallejo, Antonio (1912): La fotografía moderna. Madrid: Imprenta de J. Fernández Arias.

Cánovas del Castillo Vallejo, Antonio (1921): El retoque fotográfico. Madrid: Librería Romo.

Carabias, Mónica (2002): Tratado fotográfico sobre el retrato femenino. Antonio Cánovas Kâulak o el arte de la belleza. Madrid: Instituto de la Mujer. Ministerio de Trabajo y Asuntos Sociales.

Coloma, Isidoro (1986): La forma fotográfica. Málaga: Colegio de Arquitectos.

Fontcuberta, Joan (2000): "La fotografía catalana de 1900 a 1940". En: Introducción a la Historia de la Fotografía en Cataluña. Barcelona: Lunwerg, pp. 61-84.

García Escobar, Antonio (1907): "El arte en la fotografia". En: La Fotografia, febrero, pp. 156-160.

García Felguera, María de los Santos (2007): “Arte y fotografía (I): El Siglo XIX”. En: Historia General de la Fotografia. Madrid: Cátedra, pp. 239-255.

García Flores, Juan Manuel (1906): “Conocimientos que ha de poseer el fotógrafo”. En: La Fotografía, agosto, p. 340.

Gómez, Apeles (1910): "La Composición de la fotografía. Ante un escaparate”. En: La Fotografía, enero, pp. 126-127.

King, Carl S. (2000): "El impresionismo fotográfico en España". En: Archivos de la fotografía. Monográfico, IV (1): Zarautz: Photomuseum.

Mascarilla (1913): “Crónicas madrileñas. Las Bellezas de Kâulak”. En: La Época, 28 de febrero.

Nueda, Luis (1927): "Cháchara jocosería. Acerca de la bastardía y la legitimidad en la familia de las Bellas Artes". Sección "Fotografía Artística". En: La Esfera, marzo, p. 11

Palenque, Marta (2013): "Poesía, fotografía y tarjetas postales: Campoamor, Kâulak y Lázaro en la serie M de la colección Cánovas”. En: Correspondencia sin privacidad. Billetes, tarjetas postales y epistolas literarias en la colección Lázaro. Madrid: Fundación Lázaro Galdiano, pp. 85-103.

Picatoste, Felipe (1882): Manual de fotografia. Madrid: Biblioteca Enciclopédica Popular Ilustrada.

Puyo, Constant (1912): "La Fotografía pictórica". En: La Fotografia, diciembre, pp. 353-365.

Rivero Iglesias, Ricardo (1915): "Exposición Nacional de Fotografía Artística". En: Gran Vida, julio, pp. 185-189 y pp. 207-210.

Sánchez Vigil, Juan Miguel (2016): Kaulak. Vida y obra del fotógrafo Antonio Cánovas del Castillo Vallejo (1862-1933) [Tesis doctoral]. Ciudad Real: Universidad de Castilla La Mancha.

Sánchez Vigil, Juan Miguel; Olivera Zaldua, María (2016): "El estereotipo y la tradición en las tarjetas postales de Kaulak". En: Cabañas Bravo, Miguel; Rincón García, Wifredo Imaginarios en conflictos "los Español” en los siglos XIX y XX, Madrid: CSIC, pp. 61-78.

Scharf, Aaron (1994): Arte y Fotografia. Madrid: Alianza Editorial.

Sougez, Marie Loup (1994): Historia de la fotografia. Madrid: Cátedra.

Vega, Carmelo (2017): Fotografia en España (1839-2015): Historia, tendencias, estéticas. Madrid; Cátedra.

Zélich, Cristina (1998): La fotografia pictorialista en España. Barcelona: Fundación La Caixa.

Fecha de recepción: 3-VII-2017

Fecha de aceptación: 11-I-2018

Archivo Español de Arte, vol. XCI, n. ${ }^{\circ}$ 363, pp. 269-284, julio-septiembre 2018

ISSN: 0004-0428, eISSN: 1988-8511, https://doi.org/10.3989/aearte.2018.17 